OPEN ACCESS

Edited by:

Melissa T. Buelow,

The Ohio State University,

United States

Reviewed by:

Elizabeth Krusemark

Millsaps College, United States

Pietro Muratori,

Fondazione Stella Maris (IRCCS), Italy

*Correspondence:

Maryam Farzand

maryammalick@yahoo.com

Specialty section:

This article was submitted to

Personality and Social Psychology,

a section of the journal

Frontiers in Psychology

Received: 01 March 2021

Accepted: 31 August 2021

Published: 30 September 2021

Citation:

Farzand M, Cerkez Y and Baysen E (2021) Effects of Self-Concept on

Narcissism: Mediational Role of

Perceived Parenting.

Front. Psychol. 12:674679.

doi: 10.3389/fpsyg.2021.674679

\section{Effects of Self-Concept on Narcissism: Mediational Role of Perceived Parenting}

\author{
Maryam Farzand*, Yagmur Cerkez and Engin Baysen \\ Guidance and Counseling Psychology, Near East University, Nicosia, Cyprus
}

An increase in narcissism has been reported by experts over the years. Narcissists bring a lot of negative consequences to themselves and to the people around them. This study investigates that perceived parenting leads to the development of inflated, unstable self-concept. The inflated self-concept lays the framework for the development of narcissistic traits among individuals; perceived parenting affects this relationship. A sample of 628 adults was taken from North Cyprus through purposive sampling. Scales for perceived parenting, self-concept, and narcissism were administered. Results showed that the statistically significant variance in the self-concept is explained by perceived parenting. Both mothers and fathers contributed significantly to the development of inflated self-concept. Moreover, multiple linear regression results showed a higher significant variance in narcissistic traits due to self-concept compared with perceived parenting. Mediational tests also showed that high levels of narcissistic traits were indirectly related to self-concept through perceived parenting. The study findings have challenged the notion of only mothers being responsible for narcissistic traits among their children. The study results also suggest that targeting self-concept in individuals with narcissistic traits may be a good directive for therapeutic interventions.

Keywords: narcissism, perceived parenting, self-concept, behavior, mediation

\section{INTRODUCTION}

The family is the prime environment for behavioral development (O'Connor and Scott, 2007). Problematic families having a lack of parental warmth and concern for children, and harsh and inconsistent disciplinary practices are identified as risk factors for the development of narcissistic traits (Ormel et al., 2005; Mahajan et al., 2010; Cutuli et al., 2012; Chang, 2014; Bushman et al., 2016). Even though most of the studies talk about the parental impact on narcissistic behaviors, however, not all the children undergoing the same parental practices develop narcissistic tendencies (Finzi-Dottan and Cohen, 2010). In this study, one of the objectives to take perceived parenting into account is that people create their own realities based on their perceptions which may or may not be factual but are real for the individual. Another objective is to find if the inflated self-concept of an individual may provide the foundation leading to the development of narcissistic traits; perceived parenting interactions between the child and the parents influence this relationship.

Primarily, perceived parenting involves how individuals perceive regular interactions that a parent had in order to nurture and discipline them including certain practices that parents engage in while raising their children such as imposing certain rules, schedules, punishments, and rewards (Dixon et al., 2008; Assadi et al., 2011). Individuals fostered in an environment of parental acceptance, dialogue, and affection have a strong self-concept (Calafat et al., 2014). 
In contrast, parental coercive control reduces the self-concept of an individual (Boudreault-Bouchard et al., 2013).

Self-concept refers to the totality of a complex and dynamic system of learned attitudes, opinions, and feelings that each holds to be true about the personal existence of an individual (Tan and Yates, 2007), which remains the ultimate answer to the question, "Who am I?" Contemporary self-concept research and theory assume that individuals establish self-concept in relation to different domains making self-concept a multidimensional construct such as social, competence, affect, physical, academics, family, gender roles and sexuality, racial identity, and numerous others (Bracken, 1992; Bong and Clark, 2010). Cooley (1902) used the term looking glass self to state that other important individuals especially in the early years of an individual life serve as a mirror to which children relate and perceive themselves. He stated that associated sentiments of children of appraisals of parents of them are closely impacting the self-concept than the actual appraisals. Similarly, Mead (1934) also pointed out that we distinguished ourselves by starting to think about what significant others think of us and then incorporate their perceptions into our self-concept (Seymour, 1973).

Kohut $(1971,1977)$ and Kernberg $(1975)$ stated that parental excessive criticism and hostility lead to feelings of inadequacy in children and prevent positive self-regard to be developed. To deal with these feelings of inadequacy, children seek approval and admiration from others in order to inflate their self-worth. They also proposed that adult narcissism is actually deeprooted in early childhood experiences, and interpretation of individuals of those experiences may be explained as a defensive response toward parental disapproval and lack of acceptance (Kohut, 1966; Kernberg, 1975). In contrast, Millon $(1969,1981)$ believed that perceptions of individuals of over-permissive parenting behaviors and excessive parental indulgence are related to the development of narcissism. Brummelman et al. (2015) claimed that children learn the behavior modeled by their parents according to their understanding and internalize these beliefs that they are superior to others and entitled to special treatment ultimately leading to excessive self-love (Akers, 2000).

Narcissism is characterized by grandiosity, arrogant, or egotistical behaviors, feelings of superiority and entitlement, and a lack of concern or empathy for others (Cain and Boussi, 2020). With high levels of narcissism to be referred to as pathological, it is otherwise considered as a normally distributed personality trait (Raskin and Hall, 1979) characterized by intrapersonal and interpersonal strategies in order to maximize and protect self-esteem, that is, the general feelings about the underlying cognitions of self-worth (Morf and Rhodewalt, 2001). With much of the research work done taking self-esteem into account with respect to narcissism, very few studies are available linking self-concept with the narcissistic tendencies. While self-concept is the cognitive or descriptive component of an individual, self-esteem is simply the evaluation of those cognitions. To improve the narcissistic traits, if the self-concept, i.e., the underlying cognitions are worked on and changed, the evaluation of these cognitions (i.e., self-esteem) will also be kept in check.
The literature mainly talks about two types of narcissism, that is, vulnerable and grandiose (Rose, 2002). Vulnerable narcissists are distinguished by having self-doubt, insecurity, profound feelings of inferiority, depression, introverts, and being oversensitive to criticism (Schoenleber et al., 2011). In contrast, grandiose narcissists are extremely assertive and extroverts with the display of dominance and grandiosity (Ng et al., 2011). The focus of this study was on grandiose narcissism and its association to inflated self-concept. Perceived parenting is argued to act as an arbitrator linking the two.

As mentioned, the self-concept of individuals is affected by many factors. One of the most influencing factors is the evaluation of other people toward the individual, especially the significant others who are mainly parents in the early years of his/her life (Peterson and Rollins, 1986). Many other researchers also suggested that parenting starts to affect from early years of life (Baumrind, 1991; Jackson-Newsom et al., 2008; Park et al., 2010). Previous studies also showed inflated self-concept to be associated with a range of mental health indicators. Emmons (1984) found that narcissistic personality inventory (NPI) scores positively correlated with self-esteem, extraversion, dominance, and independence and negatively correlated with abasement, self-ideal discrepancy, neuroticism, and social anxiety. Some degree of narcissism as measured by the NPI appears to be tapping into the benefits associated with high self-esteem and may not be maladaptive. Emmons (1984) concluded that there may be a curvilinear relationship among self-evaluation, narcissism, and adjustment.

Despite a lot of work been done in the social and personality context on narcissism, it is a complex problem that is yet to find a solution in the twenty-first century (Issurdatt, 2011; MacLaren and Best, 2013; Zhang et al., 2015; Wright et al., 2017). Elevated narcissism in adults often sets up a cascade of interpersonal and mental health challenges reinforcing the need to understand its concomitants. Experiences of maltreatment and different perceived parenting styles have been implicated (Schie et al., 2020). The previous theorizing by clinical psychologists suggests that narcissism of adults may be related to parenting practices (Kernberg, 1975; Kohut, 1977); however, a lack of consensus surrounding the conceptualization of narcissism can be found.

Horton et al. (2006) studied parenting and healthy and unhealthy narcissism in-depth and found parental warmth to be positively associated with both while psychological control of parents was positively significant only with unhealthy narcissism. The lesser the parents monitored, the higher the narcissism scores tended to be. These findings were also consistent with the study carried by Winner and Nicholson (2018). Study conducted by Watson and Clark (1992) on authoritative, permissive, and authoritarian parenting styles of Baumrind (1966) showed that perceived parental authoritativeness associates with less narcissistic maladjustment, parental permissiveness associates with immature grandiosity, and authoritarianism correlates with inadequate idealization.

Otway and Vignoles (2006) studied different psychotherapeutic theories that provide a contrasting explanation of adult narcissism resulting either from parental coldness or excessive parental admiration during the early 
years of life. They found that recollections of parental coldness and excessive parental admiration predicted both overt and covert narcissism. When modeled together, the effects of each were stronger than separate. Results demonstrated that the paradoxical combination of grandiosity and fragility in adult narcissism may be explained by the combination of childhood experiences. These results are also consistent with the literature backing parental overindulgence and unchecked affection leading to narcissism (Capron, 2004; Brummelman et al., 2015).

Most of the earlier studies were related to the parenting characteristics of mothers to associate with narcissism but comparatively fewer studies were done on the role of the fathers; however, that is changing gradually with studies taking father figures and their parenting impact into consideration (Nurmi and Aunola, 2005; Kakihara et al., 2010). Similarly, much research has been done on narcissism and self-esteem while less work has been done in regard to self-concept (Ryckmann, 1993; Chang et al., 2003). This study aims to posit that parenting cannot directly affect narcissistic development without impacting and developing the pertinent inflated and unstable self-concept first, which then incite narcissistic traits, the assertion made after sifting several of the studies done on narcissism and self-esteem (Watson et al., 2010; Brummelman et al., 2018; Schie et al., 2020).

\section{METHODS}

\section{Participants and Procedure}

The purposive convenient sample of 628 adults was given the questionnaires to fill individually. Participants included 54.6\% $(N=343)$ males and $45.4 \%(N=285)$ females. Most of the literature reviews mentioned adolescence to be up to the age of 20 years while other studies mentioning adulthood to be starting from the age of 20 or 21 years (Furstenberg et al., 2004; Barzeva et al., 2019). Age 20 was overlapped between the two categories; therefore, after the committee approach, 21 years and older adults were approached from North Cyprus for this study. The maximum age of adults who participated in this study was 50 years. They were divided into three groups as follows: early adults (aged 21-30 years), early middle age (aged 31-40 years), and middle-age adults (aged $41-50$ years). About $43.6 \%$ $(N=274)$ of the participants belonged to early adults, $34.9 \%$ $(N=219)$ belonged to early middle age, and $21.5 \%(N=135)$ belonged to middle-age adults (Table $\mathbf{1}$ ).

TABLE 1 | Demographic details of the sample $(N=628)$.

\begin{tabular}{lcc}
\hline Demographic variables & $\boldsymbol{F}$ & $\%$ \\
\hline Age & & \\
$21-30$ & 274 & 43.6 \\
$31-40$ & 219 & 34.9 \\
$41-50$ & 135 & 21.5 \\
Gender & & \\
Male & 343 & 54.6 \\
Female & 285 & 45.4
\end{tabular}

All the scales utilized in this study were administrated after obtaining permissions from the respective authors. Permission was also sought from the Ethics Committee Board to carry out the research. Participants were briefed about the objective of this study. After informed consent, the participants first completed the demographic information sheet along with the research scales of Alabama Parenting Questionnaire (APQ), Six Factor Self Concept Scale (SFSCS), and NPI to complete in one sitting. They were also briefed that anonymity and confidentiality will be maintained and are free to leave if they feel so. It took approximately $20-25 \mathrm{~min}$ for the participants to fill the scales.

\section{Measures}

\section{Perceived Parenting}

Alabama Parenting Questionnaire developed by Frick (1991) is used to study perceived parenting in this study. In earlier research, the scale showed the internal consistency ranging from $\alpha=0$ 0.63-0.80 (Shelton et al., 1996). It consisted of 42 items with 9 items having 2 statements for each mother and father. It is rated using a five-point Likert-type scale $(1=$ never, $5=$ always $)$. The scale consists of five subscales, namely, positive parenting, poor monitoring, inconsistent discipline, involvement, corporal punishment, and other discipline practices. The scores on each item were added up to get a composite perceived parenting score

TABLE 2 | Descriptive statistics of Alabama Parenting Questionnaire (APQ), Narcissistic Personality Inventory, and Six Factor Self Concept Scale (SFSCS) and their subscales.

\begin{tabular}{|c|c|c|c|c|c|c|c|}
\hline \multirow[b]{2}{*}{ Variables } & \multirow[b]{2}{*}{$N$} & \multirow[b]{2}{*}{$M$} & \multirow[b]{2}{*}{$S D$} & \multirow[b]{2}{*}{0} & \multicolumn{2}{|c|}{ Score range } & \multirow[b]{2}{*}{ Skewness } \\
\hline & & & & & Potential & Actual & \\
\hline Perceived parenting & 628 & 152.39 & 17.04 & 0.75 & $51-255$ & $97-225$ & 0.38 \\
\hline \multicolumn{8}{|l|}{ (APQ) } \\
\hline Positive parenting & 628 & 19.23 & 5.17 & 0.70 & $6-30$ & $6-30$ & 2.28 \\
\hline Poor monitoring & 628 & 30.51 & 6.56 & 0.76 & $10-50$ & $12-44$ & -0.33 \\
\hline Inconsistent discipline & 628 & 15.06 & 5.05 & 0.80 & $6-30$ & $6-30$ & 0.44 \\
\hline Involvement & 628 & 58.47 & 9.69 & 0.72 & 19-95 & $26-94$ & 0.16 \\
\hline Corporal punishment & 628 & 10.19 & 2.84 & 0.69 & $3-15$ & $3-15$ & -0.41 \\
\hline Other disciplines & 628 & 18.92 & 5.21 & 0.78 & $7-35$ & $7-35$ & 0.29 \\
\hline Self-concept (SFSCS) & 628 & 139.85 & 28.59 & 0.83 & 36-252 & $74-244$ & 0.27 \\
\hline Power & 628 & 28.21 & 9.15 & 0.67 & $7-49$ & $8-48$ & 0.75 \\
\hline Task accomplishment & 628 & 22.31 & 7.23 & 0.72 & $6-42$ & $8-42$ & 0.31 \\
\hline Giftedness & 628 & 19.20 & 6.07 & 0.72 & $5-35$ & $5-35$ & -0.05 \\
\hline Vulnerability & 628 & 23.99 & 7.23 & 0.72 & $6-42$ & $6-42$ & 0.01 \\
\hline Likeability & 628 & 22.09 & 8.63 & 0.81 & $6-42$ & $6-41$ & 0.27 \\
\hline Morality & 628 & 24.05 & 9.99 & 0.74 & $6-42$ & $6-42$ & 1.09 \\
\hline Narcissism (NPI) & 628 & 25.44 & 6.52 & 0.80 & $0-40$ & $4-39$ & -0.43 \\
\hline Authority & 628 & 5.07 & 2.24 & 0.72 & $0-8$ & $0-8$ & -0.43 \\
\hline Self-sufficiency & 628 & 3.89 & 2.10 & 0.82 & $0-6$ & $0-6$ & -0.54 \\
\hline Superiority & 628 & 3.21 & 1.64 & 0.71 & $0-5$ & $0-5$ & -0.54 \\
\hline Exhibitionism & 628 & 4.20 & 2.27 & 0.79 & $0-7$ & $0-7$ & -0.37 \\
\hline Exploitativeness & 628 & 3.08 & 1.71 & 0.74 & $0-5$ & $0-5$ & -0.36 \\
\hline Vanity & 628 & 1.83 & 1.15 & 0.70 & $0-3$ & $0-3$ & -0.39 \\
\hline Entitlement & 628 & 4.16 & 2.03 & 0.83 & $0-6$ & $0-6$ & -0.66 \\
\hline
\end{tabular}


with a high score indicative of more of the construct. We also created composite scores for perceived parenting of mothers and fathers by summing the scores only on the items relevant to mothers and vice versa. The scale was seen to be internally consistent in this study ( $\alpha=0.75$; Table 2$)$.

\section{Self-Concept}

Six Factor Self Concept Scale developed by Stake (1994) is used in this study to operationalize self-concept. It consisted of 36 items with 7 -point Likert scale $(1=$ never or almost never true of you, $7=$ almost or always true of you). The scale consisted of six subscales, namely, power, task accomplishment, giftedness, vulnerability, likeability, and morality with alpha coefficients ranging between 0.76 and 0.86 (Stake, 1994; Jedouri and Rajeh, 2020). All the scores given by the participants on the items were added up to create a composite self-concept score with a high score suggesting more of the construct. The scale has an internal consistency of $\alpha=0.85$ for this study (Table 2 ).

\section{Grandiose Narcissism}

Participants filled the NPI developed by Raskin and Hall (1979) which is mostly used and effectively validated the measure of grandiose narcissism (Tamborski and Brown, 2011). It consisted of 40 items having one narcissistic and one nonnarcissistic option. A single composite narcissism score is created by counting up the number of narcissistic options with higher scores indicative of more of the construct. It has seven subscales, namely, authority, self-sufficiency, superiority, exhibitionism, exploitativeness, vanity, and entitlement with a reliability coefficient ranging from 0.74 to 0.90 (Raskin and Terry, 1988; Rosario and White, 2005). The reliability coefficient in this study is 0.80 (Table 2).

\section{Data Analysis}

Data analysis was carried out on the gathered research data using Statistical Package for the Social Sciences 25. Process version 3.5 by Andrew F. Hayes was used for mediation analysis.

\section{RESULTS}

\section{Correlations Among Study Variables}

We started by checking the correlations among perceived parenting, self-concept, narcissism, and their subscales (Table 2). Perceived parenting and self-concept were found to have moderate positive correlation, $r=0.30, p<0.01$. Perceived parenting and narcissism were also found to be positively correlated, $r=0.23, p<0.01$. Importantly, involvement, $r=0.28$, $p<0.01$; positive parenting, $r=0.33, p<0.01$; and corporal punishment subscales of APQ, $r=0.28, p<0.01$ were found to be positively correlated with self-concept. Involvement, $r=$ $0.33, p<0.01$; positive parenting, $r=0.27, p<0.01$; poor monitoring, $r=0.8, p<0.05$; and corporal punishment $r=$ $0.10, p<0.05$ subscales of APQ were also found to be positively correlated with narcissism. Poor monitoring subscale of APQ negatively correlated with task accomplishment, $r=-0.08, p<$ 0.05 and likeability subscale of SFSCS, $r=-0.11, p<0.05$. Poor monitoring was also negatively correlated with the authority, $r=-0.08, p<0.05$ and exploitativeness subscale of NPI, $r=$ $-0.10, p<0.05$.

Self-concept was found to be significantly correlated with narcissism, $r=0.51, p<0.01$, and all of its subscales. Most of the subscales of self-concept positively correlated with the subscales of NPI with significant correlations observed among task accomplishment subscale of SFSCS and authority subscale of NPI, $r=0.40, p<0.01$; likeability subscale of SFSCS and authority subscale of NPI, $r=0.69, p<0.01$; and likeability subscale of self-concept and exhibitionism subscale of NPI, $r=$ $0.44, p<0.01$ (Table 3).

\section{Age and Gender Differences on Perceived Parenting, Self-Concept, and Narcissism}

To find gender differences in APQ, SFSCS, and NPI, an independent sample $t$-test was conducted. Significant gender differences were only present for NPI $(t=0.06, p<0.05$; $d=$ $0.02)$, though the effect size was not high (Table 4), with males scoring $(M=65.46, S=6.87)$ slightly higher than females $(M=$ $65.42, S=6.08)$.

A one-way ANOVA (Hair et al., 2010) was conducted to compare the effects of age (early adulthood, early middle age, and late middle age) on perceived parenting, self-concept, and narcissism. An analysis of variance showed that the effect of age was significant on APQ, $F_{(2,625)}=10.66, p<0.001$, SFSCS, $F_{(2,625)}=60.87, p<0.001$, and NPI, $F_{(2,625)}=33.63, p<$ 0.05. Furthermore, a post-hoc test using Bonferroni for multiple comparisons to unequal group sizes revealed that participants from late middle age (41-50 years) scored high on APQ and SFSCS. Early middle age (31-40 years) scored slightly higher than late middle age on NPI while participants from early adulthood (21-30 years) scored lower than early and late middle age on all the three scales (Table 5). As age and gender differences are seen to possibly influence narcissism, they are included in the regression analysis.

\section{Perceived Parenting of Mothers and Fathers, Self-Concept, and Narcissism}

To determine if mothers and fathers have any influence on the self-concept and narcissism, regression results showed that $10 \%$ statistically significant variance in the self-concept is explained by perceived parenting of mothers while $5 \%$ statistically significant variance in the self-concept is explained by perceived parenting of fathers (Table 6). In contrast, the value of adjusted $R^{2}$ shows that $8 \%$ statistically significant variance in narcissism is explained by perceived parenting of mothers while $4 \%$ statistically significant variance in narcissism is explained by perceived parenting of fathers (Table 7).

\section{Mediational Role of Perceived Parenting}

The consistent finding in much of the narcissism literature is that both age and gender affect narcissism (Wilson and Sibley, 2011; Grijalva et al., 2015; Berenson et al., 2017; Hoertel et al., 2018); therefore, to determine the mediating role of perceived parenting between self-concept and narcissism, both age and gender were controlled. To check the role of perceived parenting (mediator) between self-concept (independent variable) 
TABLE 3 | Correlation matrix between subscales of APQ, Narcissistic Personality Inventory and its subscales, and SFSCS and its subscales $(N=628)$

\begin{tabular}{|c|c|c|c|c|c|c|c|c|c|c|c|c|c|c|c|c|c|c|c|c|c|c|}
\hline & $A P Q^{a}$ & $\operatorname{lnv}^{b}$ & p.p $p^{c}$ & p. $\mathbf{m}^{d}$ & i. $d^{\mathrm{e}}$ & c.p $p^{f}$ & o.d.p $p^{9}$ & $N P I^{h}$ & Aut ${ }^{i}$ & s.s $\mathrm{s}^{\mathrm{j}}$ & Supk & $\operatorname{Exh}^{\prime}$ & $\operatorname{Exp}^{m}$ & $\operatorname{Van}^{n}$ & $\mathrm{Ent}^{\circ}$ & SFSCS & Pow ${ }^{q}$ & t. $a^{r}$ & Gifs $^{\mathrm{s}}$ & Vult $^{t}$ & Lik $^{u}$ & Morv \\
\hline $\mathrm{APQ}^{\mathrm{a}}$ & - & $0.69^{\star \star}$ & $0.55^{\star \star}$ & $0.39^{\star *}$ & ${ }^{*} \quad 0.25^{\star \star}$ & $0.37^{\star \star}$ & $0.42^{\star \star}$ & $0.23^{\star \star}$ & $0.26^{\star \star}$ & $0.12^{*}$ & -0.01 & $0.23^{\star *}$ & * 0.03 & 0.01 & $0.11^{\star \star}$ & $0.30^{\star \star}$ & 0.06 & $0.19^{\star \star}$ & * $0.09^{*}$ & $0.16^{\star \star}$ & $0.29^{\star \star}$ & ${ }^{\star} \quad 0.15^{\star \star}$ \\
\hline Involvement & & - & $0.28^{\star \star}$ & 0.03 & -0.04 & $0.17^{\star \star}$ & $0.11^{* *}$ & $0.24^{* *}$ & $0.33^{\star *}$ & 0.07 & 0.06 & $0.19^{\star *}$ & * $\quad 0.06$ & 0.02 & $0.08^{*}$ & $0.28^{* *}$ & $0.10^{* *}$ & $0.25^{\star *}$ & 0.04 & $0.11^{\star *}$ & $0.34^{* \star}$ & * $0.11^{* \star}$ \\
\hline Positive parenting & & & - & 0.03 & -0.01 & $0.24^{\star \star}$ & $0.10^{* \star}$ & $0.32^{\star \star}$ & $0.27^{\star \star}$ & $0.21^{\star \star}$ & * -0.01 & $0.32^{\star \star}$ & 0.03 & 0.06 & $0.16^{\star \star}$ & $0.33^{* \star}$ & $0.11^{*}$ & $0.19^{* \star}$ & $0.16^{\star \star}$ & * 0.07 & $0.38^{* \star}$ & $0.22^{\star \star}$ \\
\hline Poor monitoring & & & & - & $-0.12^{*}$ & 0.06 & -0.07 & -0.06 & $-0.08^{\star}$ & 0.01 & 0.01 & -0.03 & $-0.10^{\star}$ & -0.2 & 0.01 & -0.04 & 0.02 & $-0.08^{*}$ & 0.03 & 0.05 & $-0.11^{\star}$ & -0.03 \\
\hline Inconsistent discipline & & & & & - & -0.05 & $0.10^{*}$ & 0.05 & -0.02 & 0.04 & -0.01 & $0.08^{*}$ & 0.07 & 0.01 & 0.02 & 0.03 & -0.03 & 0.06 & -0.01 & 0.07 & 0.04 & -0.01 \\
\hline Corporal punishment & & & & & & - & $0.09^{*}$ & $0.09^{\star}$ & $0.17^{\star \star}$ & 0.04 & -0.03 & $0.14^{\star *}$ & * -0.01 & 0.02 & -0.03 & $0.11^{\star \star}$ & 0.02 & 0.02 & 0.2 & 0.06 & $0.15^{\star \star}$ & * $0.11^{\star \star}$ \\
\hline Other discipline practices & & & & & & & - & -0.01 & 0.04 & -0.02 & $-0.13^{*}$ & -0.04 & 0.03 & -0.01 & 0.05 & -0.01 & $-0.09^{\star}$ & 0.04 & -0.02 & $0.05^{\star}$ & 0.02 & 0.01 \\
\hline $\mathrm{NPI}^{h}$ & & & & & & & & - & $0.54^{\star *}$ & $0.47^{\star \star}$ & * $0.43^{\star \star}$ & * $0.63^{\star *}$ & * $0.49^{\star \star}$ & $0.36^{\star \star}$ & $0.48^{\star *}$ & * $0.51^{* *}$ & $0.24^{\star *}$ & * $0.40^{* \star}$ & * $0.19^{\star *}$ & ${ }^{*} 0.14^{\star *}$ & $0.55^{\star \star}$ & $0.25^{\star \star}$ \\
\hline Authority & & & & & & & & & - & $0.20^{* \star}$ & * 0.06 & $0.15^{\star \star}$ & * $0.14^{\star \star}$ & $0.10^{\star \star}$ & 0.06 & $0.51^{* \star}$ & $0.08^{*}$ & $0.40^{\star *}$ & $0.12^{\star \star}$ & $0.18^{\star \star}$ & $0.69^{* \star}$ & * $0.27^{\star \star}$ \\
\hline Self sufficiency & & & & & & & & & & - & 0.02 & $0.14^{\star \star}$ & * $0.16^{\star}$ & $0.11^{*}$ & $0.08^{\star}$ & $0.24^{\star \star}$ & $0.10^{*}$ & $0.14^{*}$ & $0.17^{\star \star}$ & ${ }^{*} \quad 0.10^{* *}$ & $0.25^{\star \star}$ & * $0.10^{*}$ \\
\hline Superiority & & & & & & & & & & & - & $0.18^{\star \star}$ & $0.13^{* \star}$ & $0.08^{\star}$ & $0.11^{\star *}$ & $0.22^{\star \star}$ & $0.27^{\star \star}$ & $0.18^{\star \star}$ & ${ }^{*}-0.03^{*}$ & $0.03^{\star}$ & $0.17^{\star \star}$ & $0.09^{*}$ \\
\hline Exhibitionism & & & & & & & & & & & & - & $0.17^{\star \star}$ & $0.17^{\star \star}$ & $0.21^{\star \star}$ & $0.41^{* \star}$ & $0.16^{\star *}$ & * $0.33^{* *}$ & * $0.21^{* *}$ & $0.13^{\star \star}$ & $0.44^{\star \star}$ & * $0.17^{\star *}$ \\
\hline Exploitativeness & & & & & & & & & & & & & - & $0.13^{\star \star}$ & $0.13^{\star *}$ & * $0.12^{* *}$ & -0.01 & $0.14^{\star \star}$ & 0.05 & -0.04 & $0.13^{\star \star}$ & * $0.13^{\star \star}$ \\
\hline Vanity & & & & & & & & & & & & & & - & 0.04 & $0.14^{\star \star}$ & 0.04 & $0.13^{\star *}$ & $0.11^{\star *}$ & 0.04 & 0.06 & $0.11^{\star *}$ \\
\hline Entitlement & & & & & & & & & & & & & & & - & $0.12^{\star \star}$ & $0.18^{\star \star}$ & * $0.09^{*}$ & 0.04 & 0.01 & $0.09^{*}$ & 0.01 \\
\hline SFSCS ${ }^{p}$ & & & & & & & & & & & & & & & & - & $0.49^{\star \star}$ & * $0.73^{* *}$ & $0.40^{\star \star}$ & ${ }^{*} \quad 0.45^{\star \star}$ & $0.75^{\star \star}$ & $0.66^{* *}$ \\
\hline Power & & & & & & & & & & & & & & & & & - & $0.21^{\star *}$ & 0.02 & 0.07 & $0.19^{\star \star}$ & $0.11^{* *}$ \\
\hline Task accomplishment & & & & & & & & & & & & & & & & & & - & $0.17^{\star \star}$ & $0.22^{\star \star}$ & $0.51^{\text {** }}$ & $0.46^{\star \star}$ \\
\hline Giftedness & & & & & & & & & & & & & & & & & & & - & 0.06 & $0.24^{\star \star}$ & $0.13^{\star}$ \\
\hline Vulnerability & & & & & & & & & & & & & & & & & & & & - & $0.23^{\star \star}$ & * $0.08^{\star}$ \\
\hline Likeability & & & & & & & & & & & & & & & & & & & & & - & $0.40^{* *}$ \\
\hline Morality & & & & & & & & & & & & & & & & & & & & & & - \\
\hline
\end{tabular}

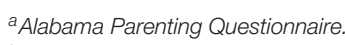

bInvolvement.

${ }^{c}$ Positive parenting.

${ }^{d}$ Poor monitoring.

eInconsistent discipline.

gother discipline practices.

${ }^{h}$ Narcissistic Personality Inventory.

iAuthority.

iself-sufficiency.

${ }^{k}$ Superiority.

mExploitativeness.

${ }^{n}$ Vanity.

${ }^{\circ}$ Entitlement.

pSix Factor Self Concept Scale.

aPower.

'Task accomplishment.

${ }^{s}$ Giftedness.

${ }^{t}$ Vulnerability.

"Likeability.

${ }^{* *} p<0.01$ and ${ }^{*} p<0.05$. 
TABLE 4 | Gender differences on parenting, self-concept, and narcissism $(N=628)$.

\begin{tabular}{|c|c|c|c|c|c|c|c|c|c|}
\hline \multirow[b]{2}{*}{ Variables } & \multicolumn{2}{|c|}{ Male $(n=343)$} & \multicolumn{2}{|c|}{ Female $(n=285)$} & \multirow[b]{2}{*}{$t_{(628)}$} & \multirow[b]{2}{*}{$p$} & \multicolumn{2}{|c|}{$95 \% \mathrm{Cl}$} & \multirow[b]{2}{*}{ Cohen's $d$} \\
\hline & $M$ & $S D$ & $M$ & $S D$ & & & $L L$ & $U L$ & \\
\hline $\mathrm{APQ}$ & 151.27 & 16.17 & 151.53 & 16.45 & -0.20 & 0.82 & -2.83 & 2.30 & 0.02 \\
\hline SFSCS & 138.26 & 28.17 & 140.70 & 26.93 & -1.11 & 0.22 & -6.79 & 1.90 & 0.09 \\
\hline NPI & 65.46 & 6.87 & 65.42 & 6.08 & 0.06 & 0.04 & -0.98 & 1.05 & 0.01 \\
\hline
\end{tabular}

TABLE 5 | Analysis of variance of adult's age (early adulthood: 21-30 years old, early middle age: 31-40 years old, and late middle age: 41-50 years old) on perceived parenting, self-concept, and narcissism $(N=628)$.

\begin{tabular}{|c|c|c|c|c|c|c|c|c|c|}
\hline \multirow[b]{2}{*}{ Variables } & & \multirow[b]{2}{*}{$M$} & \multirow[b]{2}{*}{ SD } & \multirow[b]{2}{*}{$F$} & \multirow[b]{2}{*}{$i^{1}, j^{2}, k^{3}$} & \multirow[b]{2}{*}{ Mean Diff. $\left(i^{1}, j^{2}, k^{3}\right)$} & \multirow[b]{2}{*}{ SE } & \multicolumn{2}{|c|}{$95 \% \mathrm{Cl}$} \\
\hline & & & & & & & & LB & UB \\
\hline \multirow[t]{3}{*}{ APQ } & Early adulthood ( $n=274)$ & 148.28 & 16.45 & $10.66^{\star \star \star}$ & Early adulthood < early middle age ${ }^{*}$ & $-4.35^{\star}$ & 1.45 & -7.84 & -0.86 \\
\hline & Early middle age $(n=219)$ & 152.63 & 16.67 & & NS & NS & NS & -7.28 & 1.15 \\
\hline & Late middle age $(n=135)$ & 155.69 & 14.01 & & Late middle age $>$ early adulthood ${ }^{*}$ & $7.41^{*}$ & 1.69 & 3.36 & 11.46 \\
\hline \multirow[t]{3}{*}{ SFSCS } & Early adulthood $(n=274)$ & 128.04 & 29.05 & $60.87^{\star \star \star}$ & Early adulthood < early middle age* & $-14.86^{\star}$ & 2.29 & -20.37 & -9.35 \\
\hline & Early middle age $(n=219)$ & 142.90 & 22.92 & & Early middle age $<$ late middle age ${ }^{*}$ & $-13.70^{\star}$ & 2.77 & -20.35 & -7.06 \\
\hline & Late middle age $(n=135)$ & 156.61 & 20.33 & & Late middle age $>$ early adulthood ${ }^{*}$ & $28.56^{\star}$ & 2.66 & 22.17 & 34.95 \\
\hline \multirow[t]{3}{*}{ NPI } & Early adulthood $(n=274)$ & 63.14 & 6.86 & $33.63^{\star \star \star}$ & Early adulthood < early middle age ${ }^{*}$ & $-4.10^{\star}$ & 0.56 & -5.45 & -2.75 \\
\hline & Early middle age $(n=219)$ & 67.23 & 5.721 & & NS & NS & NS & -1.62 & 1.64 \\
\hline & Late middle age $(n=135)$ & 67.22 & 5.52 & & Late middle age $>$ early adulthood ${ }^{*}$ & $4.09^{\star}$ & 0.65 & 2.52 & 5.65 \\
\hline
\end{tabular}

${ }^{1}$ number of early adults, ${ }^{2}$ number of early middle age, ${ }^{3}$ number of late middle age. ${ }^{*} p<0.05$ and ${ }^{* * *} p<0.001$.

TABLE 6 | Linear regression analysis of perceived parenting of mothers and fathers on self-concept $(N=628)$.

\begin{tabular}{lccccc}
\hline Variables & $\boldsymbol{t}$ & $\mathbf{B}$ & $\boldsymbol{\beta}$ & $\boldsymbol{F}$ & Adj. $\boldsymbol{R}^{\mathbf{2}}$ \\
\hline Intercept & $13.99^{\star \star \star}$ & 88.01 & & $68.62^{\star \star \star}$ & 0.10 \\
Mother & $8.28^{\star \star \star}$ & 1.86 & 0.31 & & \\
Intercept & $15.79^{\star \star \star}$ & 101.01 & & $37.04^{\star \star \star}$ & 0.05 \\
Father & $6.09^{\star \star \star}$ & 1.41 & 0.24 & & \\
\hline
\end{tabular}

The dependent variable for regression is self-concept. ${ }^{* \star \star} p<0.001$.

TABLE 7 | Linear regression analysis of perceived parenting of mothers and fathers on narcissism $(N=628)$.

\begin{tabular}{lccccc}
\hline Variables & $\boldsymbol{t}$ & $\mathbf{B}$ & $\boldsymbol{\beta}$ & $\boldsymbol{F}$ & Adj. $\boldsymbol{R}^{\mathbf{2}}$ \\
\hline Intercept & $36.48^{\star \star \star}$ & 54.81 & & $51.54^{\star \star \star}$ & 0.08 \\
Mother & $7.18^{\star \star \star}$ & 0.39 & 0.28 & & \\
Intercept & $38.03^{\star \star \star}$ & 57.90 & & $25.24^{\star \star \star}$ & 0.04 \\
Father & $5.02^{\star \star \star}$ & 0.28 & 0.20 & &
\end{tabular}

The dependent variable for regression is narcissism. ${ }^{* \star *} p<0.001$.

and narcissism (dependent variable), four steps devised by Baron and Kenny (1986) were followed for each mediation. These include (a) significant association between the independent variable and dependent variable, which can be mediated by a third variable, (b) significant association between independent variable and mediator, (c) significant association between the mediator and dependent variable, and (d) significant decline in independent variable and association of dependent variable when the mediator is added to the model after controlling the independent variable. For this, simple linear regression was done from the independent to dependent variable, from independent to mediator variable, and from mediator to dependent variable; then mediation is conducted. Finally, to build in confidence further on mediation findings, the Sobel test value was also calculated as advocated by MacKinnon et al. (1995).

Perceived parenting significantly mediates the direct relationship between self-concept and narcissism explaining about 28\% variance (Table 8). The direct effects from selfconcept to perceived parenting $(b=0.14, S E=0.02, p<0.001)$, from perceived parenting to narcissism $(b=0.04, S E=0.01, p<$ $0.05)$, and from self-concept to narcissism $(b=0.11, S E=0.01$, $p<0.001$ ) were positively significant (Figure 1). The indirect effect, tested using non-parametric bootstrapping (0.01), is statistically significant: $95 \% \mathrm{CI}=(0.001-0.01)$. Sobel test further validated the indirect effect of self-concept and narcissism through perceived parenting $(z=3.47, p<0.001)$.

\section{Mediational Links Between the Subscales}

To identify the unique links between the subscales of perceived parenting, self-concept, and narcissism, we regressed the total APQ subscale onto every subscale of SFSCS and NPI simultaneously and after centering all predictors and outcomes. Only involvement and positive parenting subscales of APQ predicted the relationship with narcissism significantly while other subscales did not reach significance. Thus, they are not discussed further. 
Involvement subscale of APQ mediates the direct relationship of likeability subscale of self-concept and authority subscale of narcissism significantly explaining about 53\% variance (Table 9). The direct effect from likeability to involvement $(b=0.29, S E$ $=0.04, p<0.001)$, from involvement to authority $(b=0.03, S E$ $=0.01, p<0.01)$, and from likeability to authority $(b=0.14$, $S E=0.01, p<0.001$ ) is also positively significant (Figure 2). The indirect effect $(0.01)$ is statistically significant: $95 \% \mathrm{CI}=$ (0.003-0.01). Sobel test also confirmed the significant indirect

TABLE 8 | Mediating effect of perceived parenting between self-concept and narcissism $(N=628)$.

\begin{tabular}{|c|c|c|c|c|}
\hline \multirow[b]{4}{*}{ Predictors } & \multicolumn{4}{|c|}{ Narcissism } \\
\hline & \multirow[b]{3}{*}{ Model 1 B } & \multicolumn{3}{|c|}{ Model 2} \\
\hline & & & \multicolumn{2}{|c|}{$95 \% \mathrm{Cl}$} \\
\hline & & B & $L L$ & $U L$ \\
\hline (Constant) & 129.38 & 43.97 & 39.56 & 38.38 \\
\hline Self-concept & $0.14^{\star \star \star}$ & $0.11^{\star \star \star}$ & 0.09 & 0.13 \\
\hline Perceived Parenting & & $0.04^{\star \star}$ & 0.01 & 0.07 \\
\hline Age & 1.83 & 0.62 & 0.02 & 1.23 \\
\hline Gender & -0.19 & -0.35 & -1.22 & 0.53 \\
\hline$R^{2}$ & 0.08 & 0.28 & & \\
\hline$F$ & $17.47^{\star \star \star}$ & $59.77^{\star \star \star}$ & & \\
\hline$\Delta R^{2}$ & & 0.22 & & \\
\hline$\Delta F$ & & 187.91 & & \\
\hline
\end{tabular}

$B$, unstandardized regression coefficient, $R^{2}$, explained variance; gender and age are controlled variables; ${ }^{* *} p<0.01$ and ${ }^{* \star *} p<0.001$. effect of likeability and authority through involvement $(z=2.77$, $p<0.05)$.

Positive parenting subscale of APQ mediates the direct relationship of likeability subscale of self-concept and exhibitionism subscale of narcissism significantly explaining about 23\% variance (Table 10). The direct effect from likeability to positive parenting $(b=0.22, S E=0.02, p<0.001)$, from positive parenting to exhibitionism $(b=0.09, S E=0.02$, $p<0.001)$ and from likeability to exhibitionism $(b=0.10$,

TABLE 9 | Mediating effect of involvement (perceived) between likeability (self-concept) and authority (narcissism) $(N=628)$.

\begin{tabular}{|c|c|c|c|c|}
\hline \multirow[b]{4}{*}{ Predictors } & \multirow[b]{4}{*}{ Model 1 B } & \multicolumn{3}{|c|}{ Authority } \\
\hline & & \multicolumn{3}{|c|}{ Model 2} \\
\hline & & \multirow[b]{2}{*}{ B } & \multicolumn{2}{|c|}{$95 \% \mathrm{Cl}$} \\
\hline & & & $L L$ & $U L$ \\
\hline (Constant) & 39.63 & 7.08 & 6.26 & 7.91 \\
\hline Likeability & $0.29^{\star \star \star}$ & $0.14^{\star \star \star}$ & 0.13 & 0.16 \\
\hline Involvement & & $0.03^{\star \star}$ & 0.01 & 0.05 \\
\hline Age & 0.29 & 0.57 & 0.38 & 0.75 \\
\hline Gender & -0.33 & 0.32 & 0.07 & 0.56 \\
\hline$R^{2}$ & 0.11 & 0.53 & & \\
\hline F & $26.74^{\star \star \star}$ & $172.95^{\star \star \star}$ & & \\
\hline$\Delta R^{2}$ & & 0.34 & & \\
\hline$\Delta F$ & & $476.44^{\star \star \star}$ & & \\
\hline
\end{tabular}

$B$, unstandardized regression coefficient, $R^{2}$, explained variance; gender and age are controlled variables; ${ }^{* \star} p<0.01$ and ${ }^{* \star *} p<0.001$.

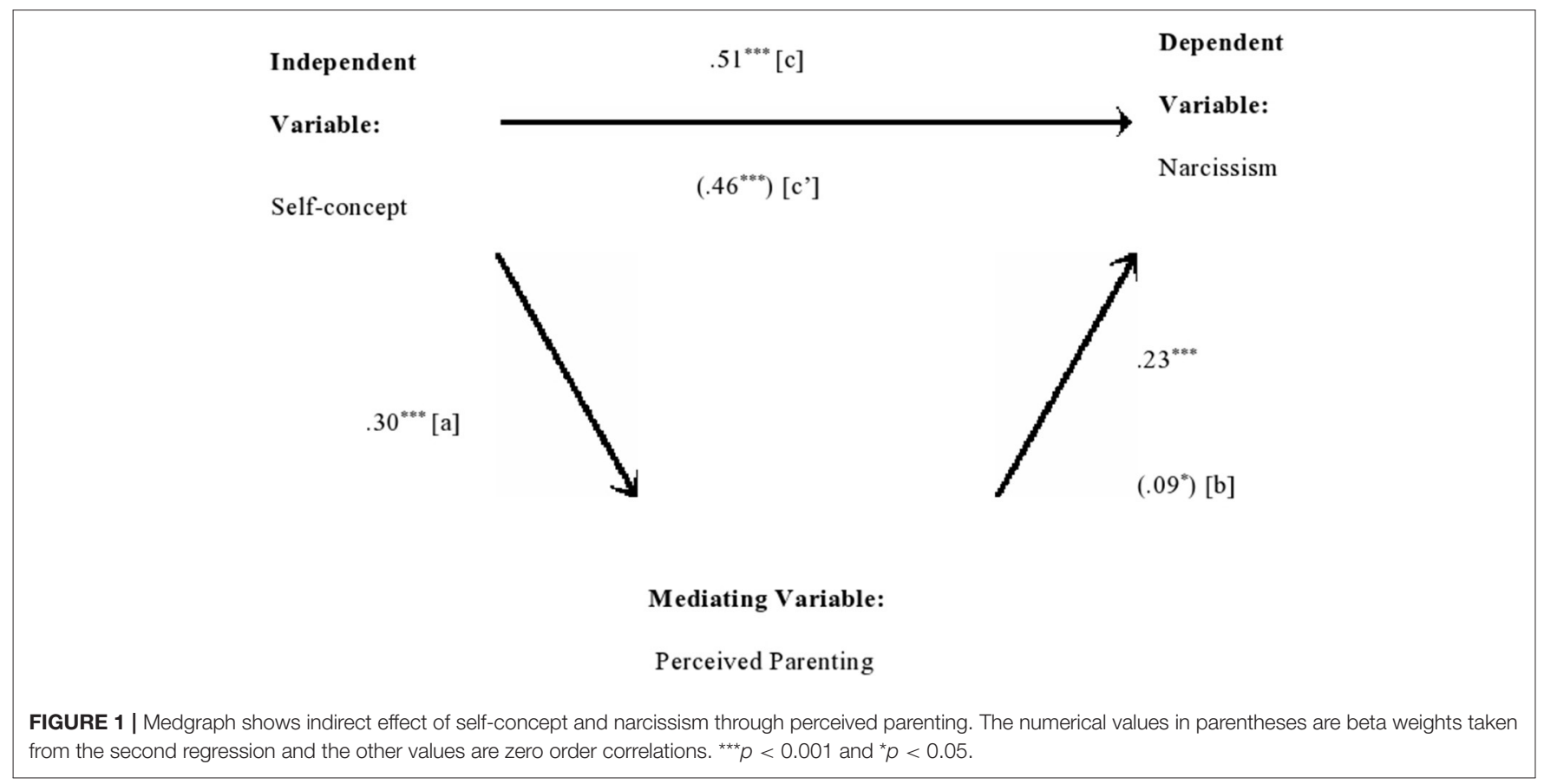




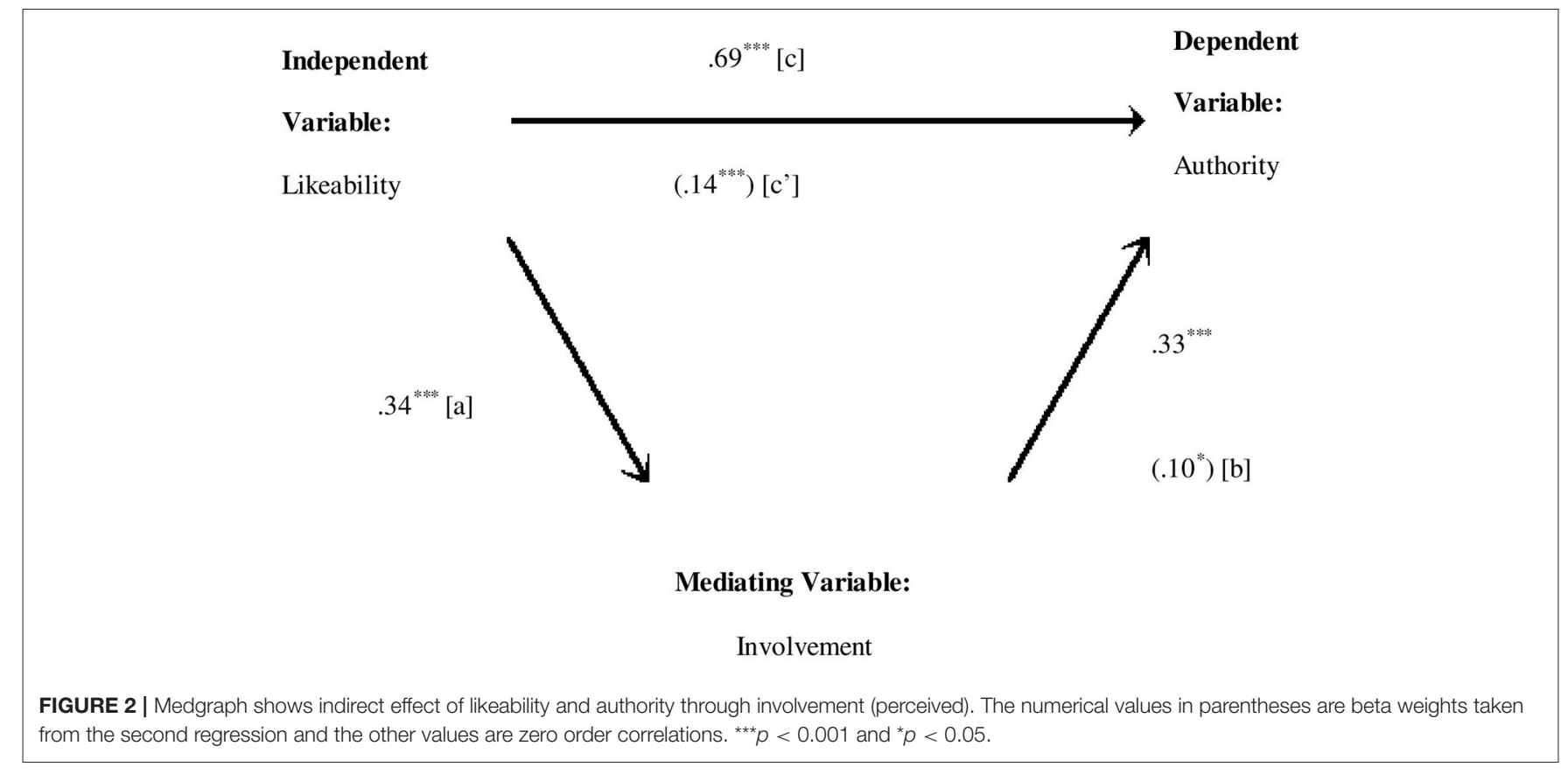

TABLE 10 | Mediating effect of positive parenting (perceived) between likeability (self-concept) and exhibitionism (narcissism) $(N=628)$.

\begin{tabular}{|c|c|c|c|c|}
\hline \multirow[b]{4}{*}{ Predictors } & \multicolumn{4}{|c|}{ Exhibitionism } \\
\hline & \multirow[b]{3}{*}{ Model $1 \mathbf{B}^{a}$} & \multicolumn{3}{|c|}{ Model 2} \\
\hline & & & \multicolumn{2}{|c|}{$95 \% \mathrm{Cl}$} \\
\hline & & B & $L L$ & $U L$ \\
\hline (Constant) & 14.52 & 8.23 & 7.39 & 9.07 \\
\hline Likeability & $0.22^{\star \star \star}$ & $0.10^{\star \star \star}$ & 0.08 & 0.13 \\
\hline Positive parenting & & $0.09^{\star \star \star}$ & 0.15 & 0.12 \\
\hline Age & -0.36 & -0.08 & -0.32 & 0.16 \\
\hline Gender & 0.23 & -0.55 & -0.87 & -0.24 \\
\hline$R^{2 b}$ & 0.15 & 0.23 & & \\
\hline$F$ & $36.95^{\star \star \star}$ & $47.43^{\star \star \star \star}$ & & \\
\hline$\Delta R^{2}$ & & 0.12 & & \\
\hline$\Delta F$ & & $94.21^{\star \star *}$ & & \\
\hline
\end{tabular}

aUnstandardized regression coefficient, bexplained variance; gender and age are controlled variables. $B$, unstandardized regression coefficient, $R^{2}$, explained variance; gender and age are controlled variables; ${ }^{* *} p<0.01$ and ${ }^{* \star *} p<0.001$.

$S E=0.01, p<0.001)$ is also positive and significant (Figure 3). The indirect effect (0.02) is statistically significant: $95 \% \mathrm{CI}=$ (0.01-0.03). Sobel test further confirmed the significant indirect effect of likeability and authority through involvement $(z=4.16$, $p<0.001)$.

\section{DISCUSSION}

The main aim of this study was to investigate the links between self-concept and narcissism with a focus on the mediational role of parenting. This study hypothesized that since all the children in a family subjected to the same parenting do not end up developing narcissistic traits, the development of relevant inflated self-concept leads to narcissism in individuals, and perceived parenting mediate that relationship. Bivariate correlations were first computed to determine the associations between the study variables. The results of this study were consistent with previous studies but also propounded on the mediational link between perceived parenting and narcissism. Total APQ was associated with self-concept and all its subscales except the power subscale. Involvement and positive parenting subscales of APQ showed significant association with the power subscale of SFSCS. This is consistent with the research finding of Clarke et al. (2004) that over-involvement and excessive pampering by parents result in child to become spoiled; they allow excessive freedom and flexibility in a soft structured environment to their children, in which parents abstain from surveilling the behavior of their children; they enforce no rules, regulations, or boundaries, which gives children too much freedom and power that they feel entitled to exercise even in later years (Clarke et al., 2004; Mueller, 2011). Parental monitoring was negatively associated with task accomplishment and likeability subscale of SFSCS. Even though this finding is in disagreement with some of the literature findings, Stattin and Kerr (2000) posited that excess parental monitoring is sometimes perceived as excessive control and intrusion by the children which makes it less effective; inconsistent parental monitoring affects self-efficacy, which indicate similar internal structures as self-concept (Bong and Clark, 2010).

Perceived parenting was also associated with narcissism and four of its components, namely, authority, self-sufficiency, exhibitionism, and entitlement. Parental monitoring was negatively associated with authority and exhibitionism of NPI which is consistent with the literature (Wetzel and Robins, 


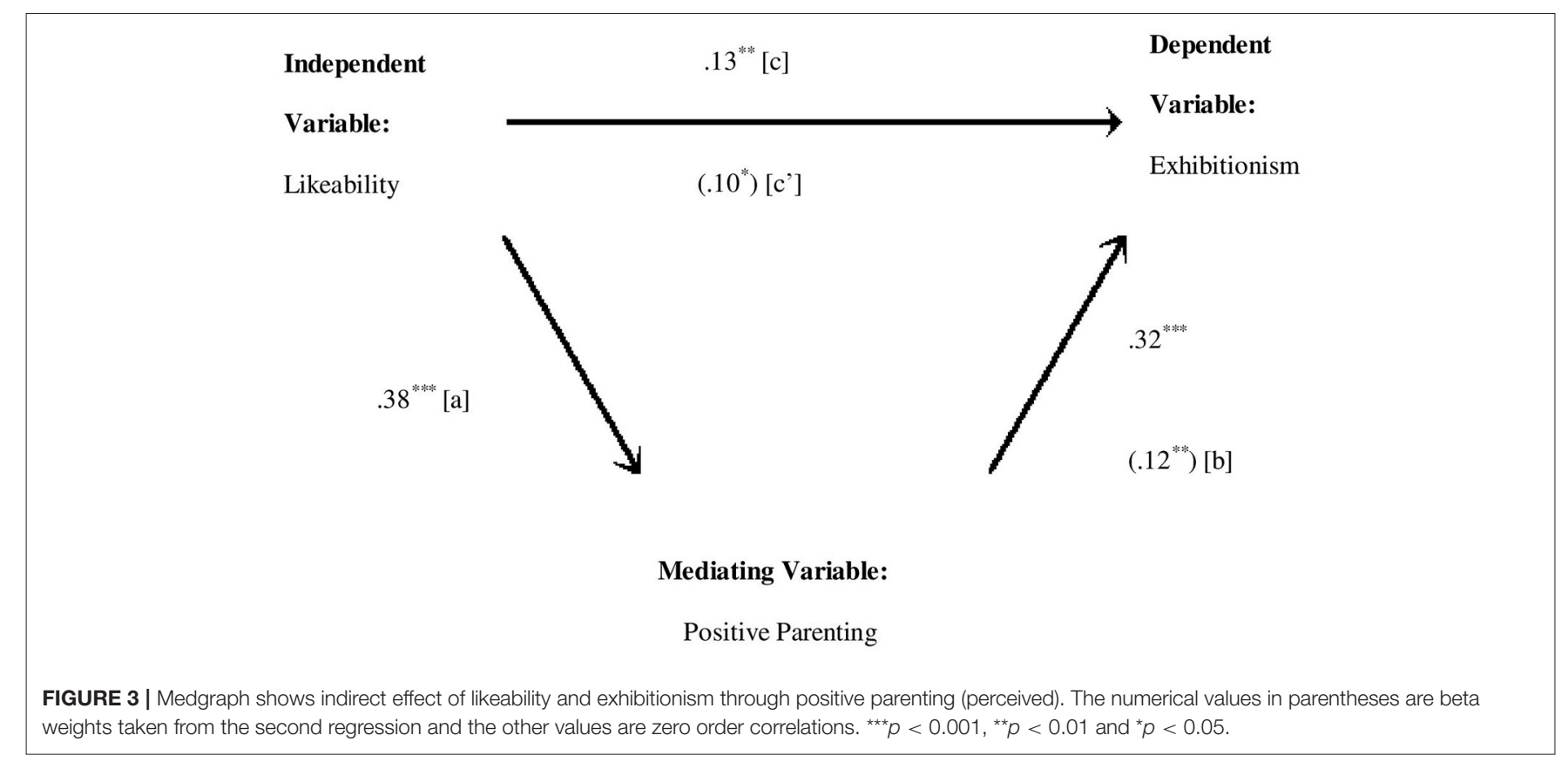

2016), while total SFSCS was significantly associated with the total NPI, and all of its subscale strengthening the hypothesized link between self-concept and narcissism. These findings again suggest that without setting appropriate boundaries, over affection enables narcissistic traits to develop. We left open the debate of whether these findings are due to the social learning theory by Millon (1969) that children develop narcissistic traits because their parents consider them more special and entitled than the rest and treat accordingly or parents fail to inculcate favorable self-regard in childhood that develops from positive mirroring (perspective of Kohut). Given that the data of this study are from early to middle-age adults, the perspective of Kohut emphasizes early childhood experiences, and the results of this study seem to be parallel with the approach of Millon. To date, the compiled research also suggests that the levels of parental monitoring and inconsistent parental practices are associated with the involvement of an individual in a range of antisocial and delinquent behaviors, narcissistic tendencies, and other personality disorders (Patterson, 1996; Dishion and McMahon, 1998; Crouter and Head, 2002). Perceived parental warmth was positively associated, and monitoring was negatively associated with both types of narcissism (Horton et al., 2006).

Existing studies on grandiose narcissism among adolescents and adults are closely related to their theoretical descriptions that narcissism, despite having some self-beneficiary aspects, has socially undesirable facets as well. Several studies done on children and adolescents have also shown that the overuse of positive reinforcement by parents may develop superiority and grandiose tendencies in children as they start to perceive themselves to be worthy of rewards and attention from others. Similar to this study, these findings are also consistent with the social learning theory by Millon that excessive praise and reward from parents strengthen entitlement and superiority in children.
Alternatively, youth with grandiose ideation about self may further elicit positive parental attention and praise (Mechanic and Barry, 2015). In a longitudinal study done by Wetzel and Robins (2016), cross-lagged relations among parental warmth, hostility and monitoring with superiority, and exploitativeness elements of narcissism were examined among adolescents. High exploitativeness level was associated with high parental hostility, whereas lower exploitativeness level was associated with low parental monitoring while none of the parenting dimensions was related to superiority. Another study done by Coppola et al. (2020) found that narcissism of both parents was positively associated with overvaluation and the narcissistic traits of children; an indirect link between the narcissistic traits of fathers and children was partially mediated by overvaluation. Positive parenting of mothers was found to have a direct positive relation to the self-esteem of the children.

While much work has been done on the association between gender and narcissism, this study also confirmed similar results (Tschanz et al., 1998; Zhou et al., 2012; Green et al., 2020). Significant age differences were present for perceived parenting, self-concept, and narcissism. Differences by age were previously found in the parenting style perception of adolescents and maladjustments of school as studied by Jaureguizar et al. (2018). Age also seemed to impact the formation of self-concept in the work done by Marsh (1989), which stated that self-concept declines from early preadolescence to middle adolescence and then increases through early adulthood (Marsh, 1989). The influence of age is also reflected on self-concept in some other studies (McCrae and Costa, 1988; Diehl and Hay, 2011). The review of previous studies gives varied results relating to the impact of age on narcissism. Some researchers claimed that traits of narcissists such as authority and independence decline with age (Danko et al., 2009) while Peruchon (2004) associated old 
age with increased narcissism arguing that narcissistic tendencies in old age may help in forming friendships and gain the social support needed (Jonason and Schmitt, 2012), and offsetting isolation or other distress backing the findings of this study shows significant age differences, with older adults having more narcissistic traits.

Then, we conducted regression analyses to determine the predictive value of both mothers and fathers on self-concept and narcissism. While much of the earlier investigations emphasized the role of mothers with stronger associations of perceived maternal parenting, some studies in recent years began to highlight the importance of the role of fathers as well (Brummelman et al., 2015; Huxley and Bizumic, 2017). Results of this study showed that both mothers and fathers predict the development of self-concept and narcissism, with mothers contributing more variance to self-concept and narcissism than fathers, which is in line with the previous work (Watson at al., 1992; Huxley and Bizumic, 2017).

There was a significant mediating effect of perceived parenting in the association between self-concept and narcissism, indicating that parenting may affect the formation of self-concept which further enhances their narcissistic traits. The mediation models suggested that the involvement subscale of APQ mediated the relationship between the likeability subscale of SFSCS and the authority subscale of NPI while the positive parenting subscale of APQ mediated the relationship between likeability of SFSCS and exhibitionism subscale of NPI. Both direct and indirect effects were positively significant. These results are parallel to the study by Pesu et al. (2016) which states that the self-concept of children is mainly derived from their parents and the beliefs of the significant others. Scientific study done by Schie et al. (2020) also advocated similar results.

Despite the limitation of cross-sectional data which may produce model fit estimates that can be overestimates, underestimates, or at best only approximate estimates of

\section{REFERENCES}

Akers, R. L. (2000). Criminological Theories. Introduction, Evaluation, and Application. Los Angeles, CA: Roxbury.

Assadi, S. M., Smetana, J., Shahmansouri, N., and Mohammadi, M. (2011). Beliefs about parental authority, parenting styles, and parent-adolescent conflict among Iranian mothers of middle adolescents. Int. J. Behav. Dev. 35, 424-431. doi: 10.1177/0165025411409121

Baron, R. M., and Kenny, D. A. (1986). The moderator-mediator variable distinction in social psychological research: conceptual, strategic, and statistical considerations. J. Pers. Soc. Psychol. 51, 1173-1182. doi: 10.1037/0022-3514.51.6.1173

Barzeva, S. A., Meeus, W. H. J., and Oldehinkel, A. J. (2019). Social withdrawal in adolescence and early adulthood: measurement issues, normative development, and distinct trajectories. J. Abnorm. Child Psychol. 47, 865-879. doi: 10.1007/s10802-018-0497-4

Baumrind, D. (1966). Effects of authoritative parental control on child behavior. Child Dev. 37, 887-907.

Baumrind, D. (1991). "Effective parenting during the early adolescent transition," in Family Transitions, eds P. Cowan and E. M. Hetherington (Hillsdale, NJ: Lawrence Erlbaum). 111-163.

Berenson, K. R., Ellison, W. D., and Clasing, R. (2017). Age differences in the desirability of narcissism. J. Individ. Differ. 38, 230-240. doi: 10.1027/1614-0001/a000240 fit, the work contributes to the growing literature on parenting, self-concept, and narcissism. Longitudinal studies in the future can give us estimates in the context of proper temporal ordering of variables. Also, this research relied on retrospective accounts of perceived parenting, a common practice in the literature (Watson et al., 1992; Horton et al., 2006; Otway and Vignoles, 2006), but there is a likelihood of inadvertent errors in memory recollection. However, it is encouraging that the findings of this study are parallel to the results of studies that solicited accounts of current parenting (Horton et al., 2006; Wetzel and Robins, 2016).

\section{CONCLUSION}

We hope that this research paves the way for further empirical evidence along the current lines to improve the understanding of how parenting affects the development of maladaptive selfconcept leading to narcissistic traits and effective parenting strategies to promote the development of healthy self-concept before unchecked narcissism may dwell into a society driven by selfishness and lacking empathy.

\section{ETHICS STATEMENT}

The studies involving human participants were reviewed and approved by Near East University Ethics Board. The patients/participants provided their written informed consent to participate in this study.

\section{AUTHOR CONTRIBUTIONS}

MF was mainly responsible for the study conceptualization, data collection, and data preparation. YC was involved in report writing and EB with the data analysis. All authors contributed to the article and approved the submitted version.

Bong, M., and Clark, R.E. (2010). Comparison between self-concept and self-efficacy in academic motivation research. Educ. Psychol. 34, 139-153. doi: 10.1207/s15326985ep3403_1

Boudreault-Bouchard, A. M., Dion, J., Hains, J., Vandermeerschen, J., Laberge, L., and Perron, M. (2013). Impact of parental emotional support and coercive control on adolescents' self-esteem and psychological distress: results of a four-year longitudinal study. J. Adolesc. 36, 695-704. doi: 10.1016/j.adolescence.2013.05.002

Bracken, B. A. (1992). Examiner's Manual for the Multidimensional Self-Esteem Scale. Austin, TX: Pro-Ed. doi: 10.1037/t01247-000

Brummelman, E., Gürel, Ç., Thomaes, S., and Sedikides, C. (2018). "What separates narcissism from self-esteem? A social-cognitive perspective," in Handbook of Trait Narcissism, eds A. Hermann, A. Brunell, and J. Foster (Cham: Springer). 47-55. doi: 10.1007/978-3-319-92171-6_5

Brummelman, E., Thomaes, S., Nelemans, S. A., Orobio, D. C. B., Overbeek, G., and Bushman, B. J. (2015). Origins of narcissism in children. Proc. Natl. Acad. Sci. U.S.A. 112, 3659-3562. doi: 10.1073/pnas.1420870112

Bushman, B. J., Newman, K., Calvert, S. L., Downey, G., Dredze, M., Gottfredson, M., et al. (2016). Youth violence: what we know and what we need to know. Am. Psychol. 71, 17-39. doi: 10.1037/a0039687

Cain, N. M., and Boussi, A. (2020). "Narcissistic personality disorder," in Encyclopedia of Personality and Individual Differences, eds V. Zeigler-Hill and T. K. Shackelford (Cham: Springer). 351-358. doi: 10.1007/978-3-319-2461 2-3_604 
Calafat, A., Gracia, F., Juan, M., Becona, E., and Andez-Hermida, J. R. F. (2014). Which parenting style is more protective against adolescent substance use? Evidence within the European context. Drug Alcoh. Depend. 1, 185-192. doi: 10.1016/j.drugalcdep.2014.02.705

Capron, E. W. (2004). Types of pampering and types of narcissistic traits. J. Individ. Psychol. 60, 76-93. Available online at: https://psycnet.apa.org/record/200412532-006

Chang, L., Mcbride-Chang, C., Stewart, S., and Au, E. (2003). Life satisfaction, selfconcept, and family relations in Chinese adolescents and children. Int. J. Behav. Dev. 27, 182-189. doi: 10.1080/01650250244000182

Chang, Y. O. (2014). Associations between adolescent-perceived parenting styles and aggressive behavior. Korean J. Youth Stud. 21, 313-341. Available online at: http://210.101.116.28/W_files/kiss10/97902039_pv.pdf

Clarke, J. I., Dawson, C., and Bredehoft, D. (2004). How Much Is Enough? New York, NY: Marlowe and Company.

Cooley, C. H. (1902). Human Nature and the Social Order. New York, NY: Scribner's, 179-185. Available online at: https://www.d.umn.edu/cla/faculty/ jhamlin/4111/Blumer/Charles\%20Horton\%20Cooley\%20-\%20Looking \%20Glass\%20Self.htm

Coppola, G., Musso, P., Buonanno, C., Semeraro, C., Iacobellis, B., Cassibba, R., et al. (2020). The Apple of daddy's eye: parental overvaluation links the narcissistic traits of father and child. Int. J. Environ. Res. Public Health 17, 1-16. doi: 10.3390/ijerph17155515

Crouter, A. C., and Head, M. R. (2002). "Parental monitoring and knowledge of children," in Handbook of Parenting: Being and Becoming a Parent, ed M. H. Bornstein (Lawrence Erlbaum Associates Publishers): New Jersey, 461-483.

Cutuli, J. J., Desjardins, C. D., Herbers, J. E., Long, J. D., Heistad, D., Chan, C., et al. (2012). Academic achievement trajectories of homeless and highly mobile students: resilience in the context of chronic and acute risk. Child Dev. 84, 841-857. doi: $10.1111 /$ cdev.12013

Danko, M., Arnaud, C., and Gely-Nargeot, M. (2009). Identity and ageing: psychosocial approaches. J. Psychol. Neuropsychiatry 7, 231-242.

Diehl, M., and Hay, E. L. (2011). Self-concept differentiation and self-concept clarity across adulthood: associations with age and psychological well-being. Int. J. Aging Hum. Dev. 73, 125-152. doi: 10.2190/AG.73.2.b

Dishion, T. J., and McMahon, R. J. (1998). Parental monitoring and the prevention of child and adolescent problem behavior: a conceptual and empirical formulation. Clin. Child Fam. Psychol. Rev. 1, 61-75. doi: 10.1023/A:1021800432380

Dixon, S. V., Graber, J. A., and Brooks-Gunn, J. (2008). The roles of respect for parental authority and parenting practices in parent-child conflict among African American, Latino, and European American families. J. Fam. Psychol. 22, 1-10. doi: 10.1037/0893-3200.22.1.1

Emmons, R. A. (1984). Factor analysis and construct validity of the narcissistic personality inventory. J. Pers. Assess. 48, 291-300. doi: 10.1207/s15327752jpa4803_11

Finzi-Dottan, R., and Cohen, O. (2010). Young adult sibling relations: the effects of perceived parental favoritism and narcissism. J. Psychol. 145, 1-22. doi: 10.1080/00223980.2010.528073

Frick, P. J. (1991). The Alabama Parenting Questionnaire. Unpublished Rating Scale, University of Alabama: Tuscaloosa, AL. doi: 10.1037/t58031-000

Furstenberg, F. F., Rumbaut, R. G., and Settersten, R. A. (2004). On the Frontier of Adulthood: Emerging Themes and New Directions. Chicago, IL: University of Chicago Press.

Green, A., MacLean, R., and Charles, K. (2020). Unmasking gender differences in narcissism within intimate partner violence. Pers. Individ. Differ. 167, 1-6. doi: $10.1016 /$ j.paid.2020.110247

Grijalva, E., Newman, D. A., Tay, L., Donnellan, M. B., Harms, P. D., Robins, R. W., et al. (2015). Gender differences in narcissism: a meta-analytic review. Psychol. Bull. 141, 261-310. doi: 10.1037/a00 38231

Hair, J., Black, J. W., Babin, B. J., and Anderson, E. R. (2010). Multivariate Data Analysis. Pearson Prentice Hall: Harlow, UK.

Hoertel, N., Peyre, H., Lavaud, P., Blanco, C., Guerin-Langlois, C., Ren,é, M., et al. (2018). Examining sex differences in DSM-IV-TR narcissistic personality disorder symptom expression using Item Response Theory (IRT). Psychiatry Res. 260, 500-507. doi: 10.1016/j.psychres.2017.12.031
Horton, R. S., Bleau, G., and Drwecki, B. (2006). Parenting narcissus: what are the links between parenting and narcissism? J. Pers. 74, 345-376. doi: 10.1111/j.1467-6494.2005.00378.x

Huxley, E., and Bizumic, B. (2017). Parental invalidation and the development of narcissism. J. Psychol. 51, 130-147. doi: 10.1080/00223980.2016.12 48807

Issurdatt, S. (2011). Gangs: A Growing Problem in Schools. Washington, DC: Social Workers Organization.

Jackson-Newsom, J., Buchanan, C. M., and McDonald, R. M. (2008). Parenting and perceived maternal warmth in European American and African American adolescents. J. Marriage Fam. 70, 62-75. doi: 10.1111/j.1741-3737.2007.00461.x

Jaureguizar, J., Bernaras, E., Bully, P., and Garaigordobil, M. (2018). Perceived parenting and adolescents' adjustment. Psicologia Reflexão e Crítica 31, 1-8. doi: $10.1186 /$ s41155-018-0088-x

Jedouri, B., and Rajeh, A. A. (2020). The reality of self-esteem among Syrian newcomers to Canada and Germany (comparative study). Int. J. Sci. Technol. Res. 9, 5045-5053. Available online at: https://www.ijstr.org/final-print/ mar2020/The-Reality-Of-Self-esteem-Among-Syrian-Newcomers-ToCanada-And-Germanycomparative-Study.pdf

Jonason, P. K., and Schmitt, D. P. (2012). What have you done for me lately? Friendship-selection in the shadow of the Dark Triad traits. Evol. Psychol. 10, 400-421. doi: 10.1177/147470491201000303

Kakihara, F., Tilton-Weaver, L., Kerr, M., and Stattin, H. (2010). The relationship of parental control to youth adjustment: do youths' feelings about their parents play a role? J. Youth Adolesc. 39, 1442-1456. doi: 10.1007/s10964-009-9479-8

Kernberg, O. F. (1975). Borderline Conditions and Pathological Narcissism. New York, NY: Jason Aronson.

Kohut, H. (1966). Forms and transformations of narcissism. J. Am. Psychoanal. Assoc. 14, 243-272. doi: 10.1177/000306516601400201

Kohut, H. (1971). The Analysis of the Self: A Systematic Approach to the Psychoanalytic Treatment of Narcissistic Personality Disorders. New York, NY: International Universities Press.

Kohut, H. (1977). The Restoration of the Self. New York, NY: International University Press.

MacKinnon, D. P., Warsi, G., and Dwyer, J. H. (1995). A simulation study of mediated effect measures. Multivar. Behav. Res. 30, 41-62. doi: 10.1207/s15327906mbr3001_3

MacLaren, V. V., and Best, L. A. (2013). Disagreeable narcissism mediates an effect of BAS on addictive behaviors. Pers. Individ. Differ. 55, 101-105. doi: 10.1016/j.paid.2013.02.004

Mahajan, S., Arora, A. K., Gupta, P., and Kapoor, S. S. (2010). Adolescent violence: an emerging challenge. J. Punjab Acad. For. Med. Toxicol. 10, 97-100. Available online at: https://www.indianjournals.com/ijor.aspx? target $=$ ijor:jpafmat\&volume $=10$ \&issue $=2$ \&article $=009$

Marsh, H. W. (1989). Age and sex effects in multiple dimensions of selfconcept: preadolescence to early adulthood. J. Educ. Psychol. 81, 417-430. doi: 10.1037/0022-0663.81.3.417

McCrae, R. R., and Costa, P. T. (1988). Age, personality, and the spontaneous self-concept. J. Gerontol. 43, 177-185. doi: 10.1093/geronj/43.6.S177

Mead, G. H. (1934). Mind, Self, and Society from the Standpoint of a Social Behaviorist. Chicago, IL: University of Chicago Press.

Mechanic, K. L., and Barry, C. T. (2015). Adolescent grandiose and vulnerable narcissism: associations with perceived parenting practices. J. Child Fam. Stud. 24, 1510-1518. doi: 10.1007/s10826-014-9956-x

Millon, T. (1969). Modern Psychopathology: A Biosocial Approach to Maladaptive Learning and Functioning. Philadelphia, PA: Saunders.

Millon, T. (1981). Disorders of Personality. New York, NY: Wiley.

Morf, C. C., and Rhodewalt, F. (2001). Unraveling the paradoxes of narcissism: a dynamic self-regulatory processing model. Psychol. Inq. 12, 177-196. doi: 10.1207/S15327965PLI1204_1

Mueller, D. K. (2011). Pampered children and the impact of parenting styles (Master's thesis). The Faculty of the Adler Graduate School, Adler Graduate School Master's Project Archive. Available online at: https:// alfredadler.edu/sites/default/files/Mueller\%20MP\%202011.pdf (accessed June 26, 2021)

Ng, H. K., Tam, K. P., and Shu, T. M. (2011). The money attitude of covert and overt narcissists. Pers. Individ. Differ. 51, 160-165. doi: 10.1016/j.paid.201 1.03 .036 
Nurmi, J. E., and Aunola, K. (2005). The role of parenting styles in children's problem behavior. Child Dev. 76, 1144-1159. doi: 10.1111/j.1467-8624.2005.00840.x-i1

O'Connor, T., and Scott, S. (2007). Parenting and Outcomes for Children. York: Joseph Rowntree Foundation.

Ormel, J., Oldehinke, A. J., Referdinand Chahartman, C. A., Dewinter, A. F., Venstra, R., and Verhulst, C. (2005). Internalizing and externalizing problems in adolescence: general and dimension-specific effects of familial loadings and preadolescent temperament traits. Psychol. Med. 35, 1825-1835. doi: 10.1017/S0033291705005829

Otway, L. J., and Vignoles, V. L. (2006). Narcissism and childhood recollections: a quantitative test of psychoanalytical predictions. Pers. Soc. Psychol. Bull. 32, 104-116. doi: 10.1177/0146167205279907

Park, Y. S., Kim, B. S. K., Chiang, J., and Ju, C. M. (2010). Acculturation, enculturation, parental adherence to Asian cultural values, parenting styles, and family conflict among Asian American College Students. Asian Am. J. Psychol. 1, 67-79. doi: 10.1037/a0018961

Patterson, G. P. (1996). "Some characteristics of a developmental theory for early onset delinquency," in Frontiers of Developmental Psychopathology, eds M. F. Lenzenweger and J. J. Haugaard (New York, NY: Oxford University Press). 81-124.

Peruchon, M. (2004). Identity and ageing: a metapsychological point of view. J. Psychol. Neuropsychiatry 2, 125-131. Available online at: https://europepmc. org/article/med/15683975

Pesu, L., Viljaranta, J., and Aunola, K. (2016). The role of parents' and teachers' beliefs in children's self-concept development. J. Appl. Dev. Psychol. 44, 63-71. doi: 10.1016/j.appdev.2016.03.001

Peterson, G., and Rollins, B. (1986). "Child socialization: a review of research and application of symbolic interaction concepts," in Handbook of Marriage and Family, eds M. Sussman and S. Steinmetz (New York, NY: Plenum). 471-507. doi: 10.1007/978-1-4615-7151-3_18

Raskin, R., and Terry, H. (1988). A principal-components analysis of Narcissistic Personality Inventory and further evidence of its construct validity. J. Pers. Soc. Psychol. 54, 890-902. doi: 10.1037/0022-3514.54.5.890

Raskin, R. N., and Hall, C. S. (1979). A narcissistic personality inventory. Psychol. Rep. 45, 590-590. doi: 10.2466/pr0.1979.45.2.590

Rosario, P. M. D., and White, R. M. (2005). The narcissistic personality inventory: test-retest stability and internal consistency. Pers. Individ. Differ. 39, 1075-1081. doi: 10.1016/j.paid.2005.08.001

Rose, P. (2002). The happy and unhappy faces of narcissism. Pers. Individ. Differ. 33, 379-391. doi: 10.1016/S0191-8869(01)00162-3

Ryckmann, R. M. (1993). Theories of Personality, 5th Edn. Brooks/Cole Publishing Co: California.

Schie, C. C. V., Jarman, H. L., Huxley, E., and Grenyer, B. F. S. (2020). Narcissistic traits in young people: understanding the role of parenting and maltreatment. Borderl. Pers. Disorder Emot. Dysregul. 7, 1-10. doi: 10.1186/s40479-020-00125-7

Schoenleber, M., Sadeh, N., and Verona, E. (2011). Parallel syndromes: two dimensions of narcissism and the facets of psychopathic personality in criminally involved individuals. Pers. Disord. Theor. Res. Treat. 2, 113-127. doi: $10.1037 / \mathrm{a} 0021870$

Seymour, E. (1973). The self-concept revisited: or a theory of a theory. Am. Psychol. 28, 404-416. doi: 10.1037/h0034679

Shelton, K. K., Frick, P. J., and Wootton, J. (1996). Assessment of parenting practices in families of elementary school-age children. J. Clin. Child Psychol. 25, 317-329. doi: 10.1207/s15374424jccp2503_8

Stake, J. E. (1994). Development and validation of the six-factor self-concept scale for adults. Educ. Psychol. Measur. 54, 56-72. doi: $10.1177 / 0013164494054001006$

Stattin, H., and Kerr, M. (2000). Parental monitoring: a reinterpretation. Child Dev. 71, 1072-1085. doi: 10.1111/1467-8624.00210
Tamborski, M., and Brown, R. P. (2011). "The measurement of trait narcissism in social-personality research," in The Handbook of Narcissism and Narcissistic Personality Disorder: Theoretical Approaches, Empirical Findings, and Treatments, eds W. K. Campbell and J. D. Miller (John Wiley and Sons, Inc.): New Jersey, 133-140. doi: 10.1002/978111809310 8.ch11

Tan, J. B. Y., and Yates, S. M. (2007). A Rasch analysis of the academic self-concept questionnaire. Int. Educ. J. 8, 470-484. Available online at: https://files.eric.ed. gov/fulltext/EJ834282.pdf

Tschanz, B. T., Morf, C. C., and Turner, C. W. (1998). Gender differences in the structure of narcissism: a multi-sample analysis of the narcissistic personality inventory. Sex Roles 38, 863-870. doi: 10.1023/A:10188334 00411

Watson, D. and Clark, L. A. (1992). Affects separable and inseparable: on the hierarchical arrangement of the negative affects. J. Pers. Soc. Psychol. 62, 489-505.

Watson, P. J., Hickman, S. E., Morris, R. J., Milliron, T., and Whiting, L. (2010). Narcissism, self-esteem, and parental nurturance. J. Psychol. 129, 61-73. doi: $10.1080 / 00223980.1995 .9914948$

Watson, P. J., Little, T., and Biderman, M. D. (1992). Narcissism and parenting styles. Psychoanal. Psychol. 9, 231-244. doi: 10.1037/h00 79344

Wetzel, E., and Robins, R. W. (2016). Are parenting practices associated with the development of narcissism? Findings from a longitudinal study of Mexicanorigin youth. J. Res. Pers. 63, 84-94. doi: 10.1016/j.jrp.2016.05.005

Wilson, M. S., and Sibley, C. G. (2011). 'Narcissism creep?' Evidence for age-related differences in narcissism in the New Zealand general population. N. Zeal. J. Psychol. 40, 89-95.

Winner, N.A., and Nicholson, B.C. (2018). Overparenting and narcissism in young adults: the mediating role of psychological control. J. Child Fam. Study 27, 3650-3657. doi: 10.1007/s10826-018-1176-3

Wright, A. G. C., Stepp, S. D., Scott, L. N., Hallquist, M. N., Beeney, J. E., Lazarus, S. A., et al. (2017). The effect of pathological narcissism on interpersonal and affective processes in social interactions. J. Abnorm. Psychol. 126, 898-910. doi: $10.1037 /$ abn0000286

Zhang, H., Wang, Z., You, X., Lü, W., and Luo, Y. (2015). Associations between narcissism and emotion regulation difficulties: respiratory sinus arrhythmia reactivity as a moderator. Biol. Psychol. 110, 1-11. doi: 10.1016/j.biopsycho.2015.06.014

Zhou, H., Li, Y., Zhang, B., and Mou, Z. (2012). The relationship between narcissism and friendship qualities in adolescents: gender as a moderator. Sex Roles 67, 452-462. doi: 10.1007/s11199-012-0169-8

Conflict of Interest: The authors declare that the research was conducted in the absence of any commercial or financial relationships that could be construed as a potential conflict of interest.

Publisher's Note: All claims expressed in this article are solely those of the authors and do not necessarily represent those of their affiliated organizations, or those of the publisher, the editors and the reviewers. Any product that may be evaluated in this article, or claim that may be made by its manufacturer, is not guaranteed or endorsed by the publisher.

Copyright $\odot 2021$ Farzand, Cerkez and Baysen. This is an open-access article distributed under the terms of the Creative Commons Attribution License (CC BY). The use, distribution or reproduction in other forums is permitted, provided the original author(s) and the copyright owner(s) are credited and that the original publication in this journal is cited, in accordance with accepted academic practice. No use, distribution or reproduction is permitted which does not comply with these terms. 